\title{
The Evolution of Temporal and Spatial Patterns of Carbon Monoxide Concentrations in the Metropolitan Area of Sao Paulo, Brazil
}

\author{
Flavia Noronha Dutra Ribeiro, ${ }^{1}$ Delhi Teresa Paiva Salinas, ${ }^{1}$ \\ Jacyra Soares, ${ }^{2}$ Amauri Pereira de Oliveira, ${ }^{2}$ Regina Maura de Miranda, ${ }^{1}$ \\ and Luana Antunes Tolentino Souza ${ }^{1}$ \\ ${ }^{1}$ School of Arts, Sciences and Humanities of the University of Sao Paulo (EACH-USP), Av. Arlindo Béttio 1000, Ermelino Matarazzo, \\ 03828-000 Sao Paulo, SP, Brazil \\ ${ }^{2}$ Institute of Astronomy, Geophysics and Atmospheric Sciences of the University of Sao Paulo (IAG-USP), Rua do Matão 1226, \\ Cidade Universitária, 05508-090 Sao Paulo, SP, Brazil
}

Correspondence should be addressed to Flavia Noronha Dutra Ribeiro; flaviaribeiro@usp.br

Received 15 April 2016; Revised 17 July 2016; Accepted 10 August 2016

Academic Editor: Ilan Levy

Copyright ( 2016 Flavia Noronha Dutra Ribeiro et al. This is an open access article distributed under the Creative Commons Attribution License, which permits unrestricted use, distribution, and reproduction in any medium, provided the original work is properly cited.

\begin{abstract}
The Environmental Agency of Sao Paulo has a large dataset of carbon monoxide measurements: 20 years of records in 18 automatic stations inside the metropolitan area. However, a thorough investigation on the time evolution of CO concentration tendency and cycles also considering spatial variability is lacking. The investigation consists of a trend line analysis, a periodogram analysis, a correlation between CO concentration and meteorological variables, and spatial distribution of CO concentration. Local and federal policies helped in decreasing $\mathrm{CO}$ concentrations and the highest decreasing rate was $0.7 \%$ per month. This tendency is lately stabilizing, since the vehicles fleet is increasing. CO most relevant cycles are annual and diurnal and a few series indicate a weekly cycle. Diurnal cycle shows two peaks, morning and evening rush hours, 1.2 and $1.1 \mathrm{ppm}$, respectively, in 2012 . However, lately there is an extended evening peak $(20 \mathrm{~h}$ to $23 \mathrm{~h})$, related to changes in emission patterns. The spatial analysis showed that $\mathrm{CO}$ concentration has high spatial variability and is influenced by proximity to heavy traffic and vegetated areas. The present work indicates that several processes affect $\mathrm{CO}$ concentration and these results form a valuable basis for other studies involving air quality modeling, mitigation, and urban planning.
\end{abstract}

\section{Introduction}

Air pollution caused by particulate matter (PM), which includes nitrates, sulfates, and black carbon, has been increasing in urban areas, particularly in low and middle-income cities [1]. The excess of air pollutants has adverse impacts on the population health, affecting mainly the respiratory and cardiovascular systems [1-4]. Carbon monoxide, for instance, reacts with the hemoglobin in the blood and interferes with the oxygen transport, being also associated with low weight newborns and fetal death [5]. One of the major sources of air pollution in metropolitan areas is vehicular [1].

The Metropolitan Region of Sao Paulo (MRSP) is formed by 39 cities, including Sao Paulo $\left(23^{\circ} 32^{\prime} 56^{\prime \prime} \mathrm{S}, 46^{\circ} 38^{\prime} 20^{\prime \prime} \mathrm{W}\right)$, the largest city in the South Hemisphere, and has deteriorated air quality that increases the mortality of its 21 million inhabitants [6]. The climate of Sao Paulo is characterized by a wet summer and a dry winter [7]. According to the Environmental Agency of Sao Paulo (CETESB), the major source of air pollution in the MRSP is vehicular emission, since the MRSP concentrates $49 \%$ of the vehicular fleet of the state in only $3.2 \%$ of its area. Every year, mobile and stationary pollution sources emit 132,000 tons of CO, 42,000 tons of hydrocarbons (HC), 77,000 tons of $\mathrm{NO}_{x}, 4,500$ tons of PM, and 11,000 tons of sulfur oxides $\left(\mathrm{SO}_{x}\right)$, and the vehicles are responsible for $40 \%$ of $\mathrm{PM}$ emissions, $48 \%$ of $\mathrm{SO}_{x}, 80 \%$ of $\mathrm{NO}_{x}, 81 \%$ of $\mathrm{HC}$, and $97 \%$ of $\mathrm{CO}$. In the last decade, the fleet 
has grown with a $100 \%$ higher rate than before and now has an annual growth rate of $6 \%$. Until the middle of the last decade, fuel sales were also increasing at an annual rate of $10 \%$. However, the fuel consumption is now stabilizing [8].

The major source of $\mathrm{CO}$ and $\mathrm{HC}$ is light vehicles and, according to the Environmental Agency (CETESB), in 2014 the MRSP vehicular fleet was composed of 6.1 million lightduty vehicles (5.1 million private and 1 million commercial), 181 thousand heavy-duty vehicles, 57 thousand buses, and 896 thousand motorcycles [9]. Light-duty vehicles were responsible for $75 \%$ of CO emissions, heavy-duty were responsible for approximately $2 \%$, buses for less than $2 \%$, and motorcycles for $21 \%$ [9].

The temporal and spatial variation of $\mathrm{CO}$ concentration is dependent on meteorological conditions as well as emissions patterns. Meteorological conditions are influenced by phenomena of different scales, as the diurnal evolution of the Planetary Boundary Layer (PBL), sea breeze, and synoptic fronts. Emission patterns are influenced by commercial days and hours, vehicle and fuel sales, and a variety of public policies (aiming on mobility, emission, production of vehicles, availability of fuel types, etc.).

A weekly cycle in $\mathrm{CO}$ concentration, an indication of vehicular emission influence, has been observed in many urban areas, including Sao Paulo, when the concentration is minimum during the weekend and then maximum on working days $[8,10,11]$. Maximums also occur during rush hours, reinforcing the modulation of $\mathrm{CO}$ concentration by traffic emission [8, 11]. Also, observations of CO concentration are strongly influenced by the proximity to traffic corridors [12].

The influence of meteorological processes can be noticed by the diurnal and seasonal variability observed in $\mathrm{CO}$ concentration time series. Zvyagintev et al. [11] investigated the variations of air pollutants in London and observed that $\mathrm{CO}$ concentration is maximum during the cold season and in the morning rush hour. They also observed that the vertical mixing strongly influences the seasonal and diurnal variation of the pollutants concentration. Kramar et al. [13] have found a similar result for the pollutants in Moscow, where solar-induced convection moderates the concentration levels after sunrise, when the PBL develops, and enhances the concentration when the convective mixing stops after sunset, when the PBL collapses. Carvalho et al. [8] observed maximum concentration of $\mathrm{CO}$ during the evening rush hour, closely followed by another peak during the morning rush hour, for the MRSP, when averaging from 1996 and 2009.

The elevated concentrations of atmospheric pollutants and the concerns about greenhouse gases emissions lead to the development of public policies that aimed to reduce these emissions. Therefore, in 1986, the National Environmental Council of Brazil (CONAMA) created the Vehicular Air Pollution Control Program (PROCONVE) that established limits for the vehicular emission and forced the development of new technologies regarding fuels, engines, and car parts [14]. For light vehicles, PROCONVE implemented 5 phases starting in 1998 that would gradually decrease the emission factors of pollutants by the engines.

PROCONVE has proved to help decrease CO concentration in the MRSP, where it has not exceeded the air

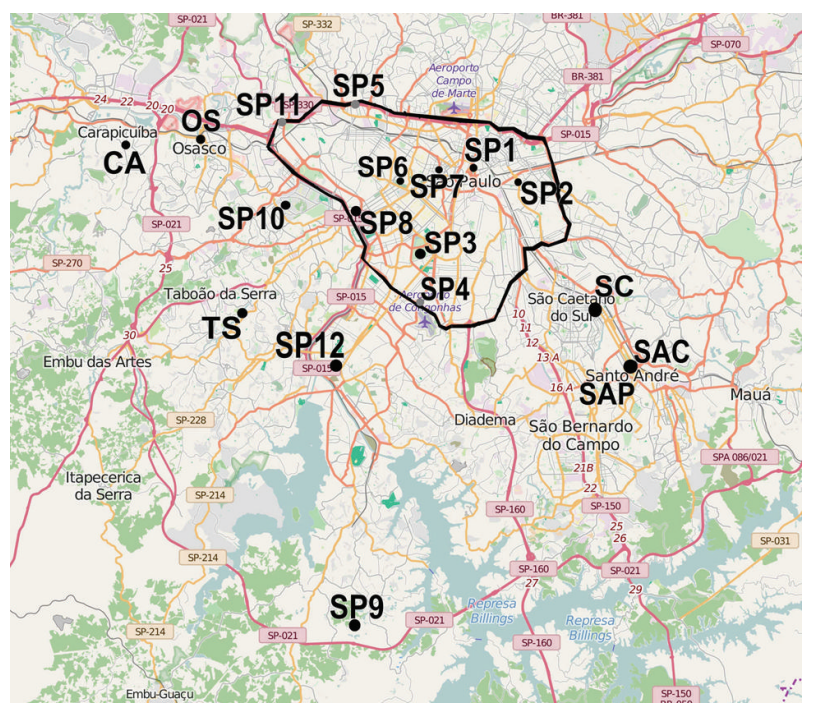

$\begin{array}{ll}\text { SP1: PD Pedro II } & \text { SP10: IPEN-USP } \\ \text { SP2: Moóca } & \text { SP11: Marginal Tiete-Ponte dos Remedios } \\ \text { SP3: Ibirapuera } & \text { SP12: Santo Amaro } \\ \text { SP4: Congonhas } & \text { CA: Carapicuíba } \\ \text { SP5: Lapa } & \text { OS: Osasco } \\ \text { SP6: Cerqueira César } & \text { TS: Taboão da Serra } \\ \text { SP7: Centro } & \text { SC: Sao Caetano do Sul } \\ \text { SP8: Pinheiros } & \text { SAC: Santo Andre Centro } \\ \text { SP9: Parelheiros } & \text { SAP: Santo Andre Paco Municipal }\end{array}$

FIGURE 1: Spatial distribution of the monitoring stations in the MRSP. Each marker represents a station that has recorded $\mathrm{CO}$ concentration between 1996 and 2013. Black thick line represents the traffic restriction area for light-duty vehicles. SAC and SAP stations are very close and are represented by the same marker. SAP has substituted SAC station (source: OpenStreetMap, 06 Jul 2016).

quality standard limit since 2008 and presents a decreasing tendency. Carvalho et al. [8] observed a decrease in $90 \%$ of pollutants emitted by light-duty vehicles from 1991 to 2010 due to this program. Pérez-Martínez et al. [15] observed that $\mathrm{CO}$ concentration decreased despite the increase in lightduty vehicle fuel sales. However, $\mathrm{CO}$ concentration is now stabilizing [16], raising again the necessity of investigating this pollutant.

Since vehicular emission is also linked to mobility problems in urban areas, other public policies have been implemented locally. In the city of Sao Paulo, vehicles are restricted in the center of the city (delimited by the thick black line in Figure 1) during rush hours [17], from 0700 local time (LT) to $1000 \mathrm{LT}$ and from $1700 \mathrm{LT}$ to $2000 \mathrm{LT}$, for one weekday, based on the last digit of the vehicle plate, since October 1997 (M. L. 12.490/97). There are also restrictions for heavy vehicles, during rush hours (M. L. 14.751/08). An inspection program was created in 2009 and discontinued in 2014 to condition the renovation of the vehicles licenses on the attainment of standard emissions (M. D. 50.232/08). Recently, a total of $440 \mathrm{~km}$ of dedicated bus lanes and $100 \mathrm{~km}$ of bicycle paths and lanes were implemented in Sao Paulo 
city and are expected to decrease the use of private vehicles as transportation [18].

On the other hand, the vehicular fleet in the MRSP was estimated to be over 7 million vehicles ( 5 million light vehicles) in 2013 [19]. From 2006 to 2013, the federal government reduced the taxes on new vehicles twice, in an attempt to improve economy; however Wilbert et al. [20] concluded that it is not possible to state that the reduction of taxes exclusively increased the number of new cars sales and that other economic phenomena also helped in increasing these numbers.

CETESB has been monitoring the air quality since 1970s and has recorded $\mathrm{CO}$ measurements in 18 monitoring stations in the MRSP, providing a relevant dataset for analysis of longterm variations in $\mathrm{CO}$ concentration patterns and spatial variability. However, to our best knowledge, studies using this dataset have focused on linear trends or cycles representing an average behavior for the MRSP $[8,15]$. This approach is useful to give a generalized behavior; however it does not allow for spatial variability analysis. The previous works also do not evaluate how the diurnal and annual cycles of $\mathrm{CO}$ concentration have changed. Therefore, the present study aims to perform a more complete exploration of the $\mathrm{CO}$ concentration evolution in time, using nonlinear fits for trend analysis, investigating the most important $\mathrm{CO}$ cycles and their evolution in time, and correlating $\mathrm{CO}$ concentration to meteorological variables, while also considering the spatial variability, by analyzing each station series separately and investigating their local characteristics. Since CO is mostly emitted by light-duty vehicles in Sao Paulo and is considered an inert tracer with an average lifetime of two weeks to two months [21], its concentration patterns may provide valuable information regarding the effect of public policies on lightduty emissions. The result is a thorough analysis of $\mathrm{CO}$ concentration in the MRSP that can be used by other studies, such as air quality modeling, air quality mitigation, public policies effectiveness, decision-making, and planning. The datasets, stations characteristics, and the methodology of the analysis are presented in Section 2. Section 3 presents the results and discussion and the conclusions are presented in Section 4.

\section{Methodology}

This work used the database from CETESB, from 1 May 1996 to 30 Jun 2013. The database comprises 33 automatic monitoring stations inside the MRSP and, from this total, 18 stations have recorded CO concentrations, although some stations were installed after 1996 and others were closed before 2013. SP1, SP3, SP4, SP6, and OS stations (Figure 1 and Table 1) have the longest time series, beginning in May 1996 and still recording, and SP11 has the shortest series, beginning in September 2012. Therefore, SP11 station was only included in the investigation of the correlation to the meteorological variables. The spatial distribution of the monitoring stations can be observed in Figure 1 and their characteristics are presented on Table 1.
Nondispersive infrared sensors are used to measure CO concentrations and an hourly average is recorded with only 1 significant digit after the decimal point. To insure the quality of the measurements, the hourly average is recorded only when at least $75 \%$ of the measurements are valid $[16,19]$.

There are 12 stations inside Sao Paulo city (SP1 to SP12), distributed among all the 5 zones of the city (north, east, south, west, and center), though more concentrated in the center and less concentrated in the east and south zones, and 6 stations in surrounding cities (SC, SAC, OS, TS, CA, and $\mathrm{SAP})$, as displayed in Figure 1.

The database for each station has hourly averages of pollutants concentrations and meteorological variables obtained simultaneously. However, most of the series does not have the 0500 LT average because the sensors are usually calibrated at this time of the day. The data recorded since 1998 can now be accessed at the Environmental Agency website [22] and the data from 1996 to 1997 were obtained through contact with the Agency.

2.1. Trend Line Analysis. To better understand the trend in $\mathrm{CO}$ concentration, taking into account spatial differences, a tendency analysis was performed for each monitoring station. Monthly averages were calculated for each station and time series with these averages were produced. After that, a trend line was fitted and the coefficient of determination $\left(R^{2}\right)$ was compared for linear, exponential, logarithmic, power, and second- and third-degree polynomial curves. The best fit was considered the one with higher $R^{2}$ and the thirddegree polynomial was tested only when the second-degree polynomial was the best fit among the other types of curves. A hypothesis test was performed with a confidence interval of $95 \%$ for the calculations of $R^{2}$ for the exponential fit. Therefore, $p$ values smaller than or equal to 0.05 indicated that the null hypothesis is rejected. The null hypotheses $\left(H_{0}\right)$ represented the case where the calculated coefficient does not have statistical significance.

2.2. Periodogram Analysis. A periodogram analysis was performed to investigate the most important periods of variation in $\mathrm{CO}$ concentration, using a python function (scipy.signal.periodogram). The periodogram represents the Fourier Power Spectrum Density of a time series and was used to find periodicity in $\mathrm{CO}$ concentration time series. This method uses a Fast Fourier Transform (FFT) technique to calculate the discrete Fourier transform of the time series and estimates the spectrum with the squared magnitude of this transform [23].

The hourly average series were investigated to find gaps, since only a complete series could be used in the periodogram analysis. When there was only one record missing, for example, at $0500 \mathrm{LT}$ (that was usually missing), it was filled by the average between the previous and the following record. If the previous or the following record were missing and there was at least three records for the same hour in the same month, the gap was filled by the average of the concentrations at the same hour of the same month. If a gap greater than 27 days was found, the series was divided. For example, SP1 station time 


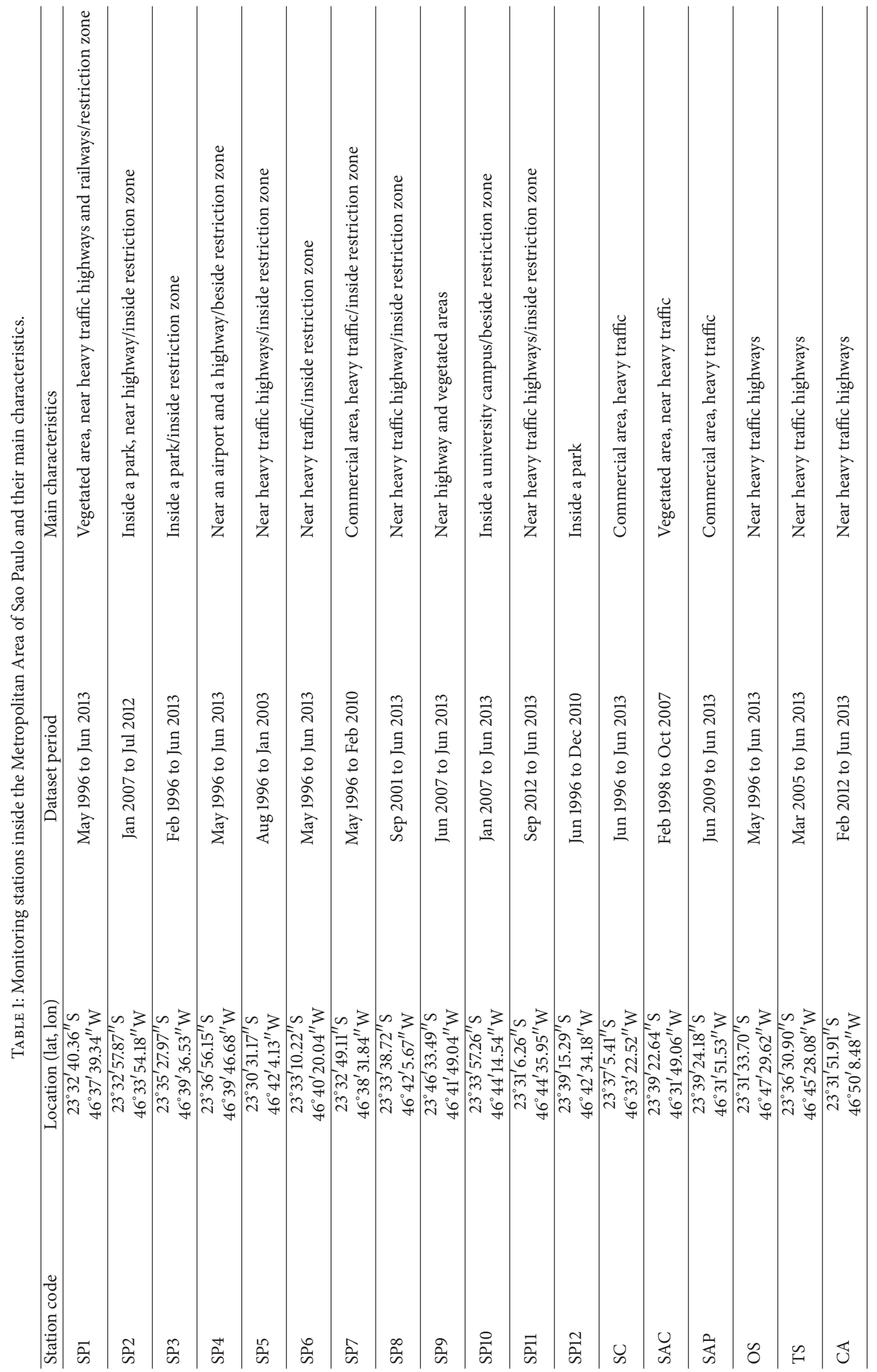




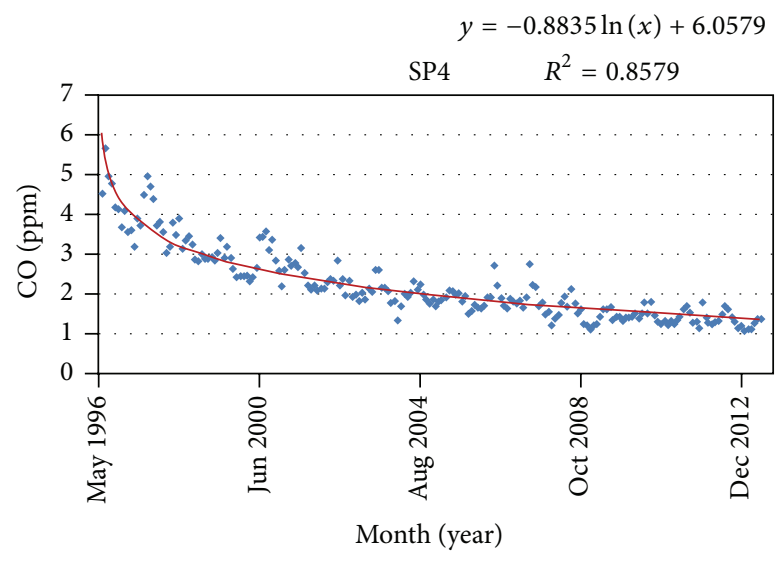

(a)

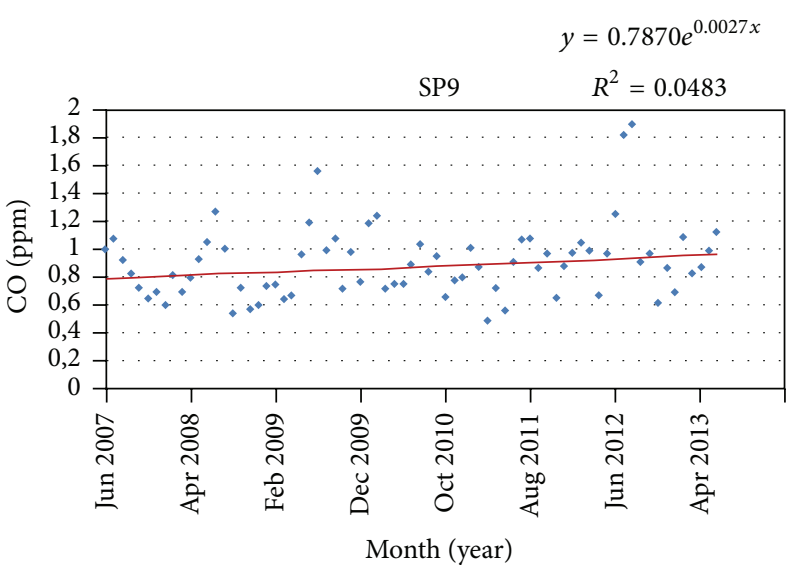

(b)

FIGURE 2: Scatter plot of monthly averages for stations (a) SP4 and (b) SP9. Red dotted line in the trend line follows the function $y$ and $R^{2}$ is the coefficient of determination.

series began in May 1996, but presented 3 gaps (from 1 Feb 1998 to 28 Feb 1998, from 4 Feb 2004 to 30 Set 2005, and from 1 Aug 2008 to 31 Dec 2008) and then produced 4 different time series to be used in the periodogram analysis. Only series with more than 10,000 records were considered. After that, the periodogram was produced for each of the 29 resulting series and the 7 highest peaks were indicated. The peaks represent the periods with higher power spectrum density that indicate the more significant periodical variations in the time series. To complement this analysis, hourly and monthly averages were calculated for different years, to provide annual and diurnal cycles.

2.3. Correlation to Meteorological Variables. The correlation between $\mathrm{CO}$ concentration and the meteorological variables was calculated using the available monthly averages and a hypothesis test was performed with a confidence interval of $95 \%$. Again, $p$ values smaller than or equal to 0.05 indicated that the null hypothesis is rejected. The null hypotheses $\left(H_{0}\right)$ represented the case where the calculated correlation coefficient $(r)$ does not have statistical significance. Only stations that had recorded $\mathrm{CO}$ concentration and one of the meteorological variables simultaneously were considered, totalizing 7 stations for air relative humidity and air temperature (SP1, SP3, SP8, SP9, SP11, CA, and SC) and 11 for wind velocity (SP1, SP2, SP3, SP5, SP8, SP11, SP12, OS, SC, CA, and SAC).

Then, a multivariate analysis was performed for 6 stations that recorded all the 3 variables and CO concentration (SP1, SP3, SP8, SP11, CA, and SC) using monthly averages. A regression equation relating all the 4 variables was found for each station, with a confidence interval of $95 \%$. When a variable presented a $p$ value greater than 0.005 , another equation was performed without the variable to achieve the 95\% confidence interval.

2.4. Spatial Distribution. Annual averages of CO concentration were calculated for each station and then a diagram was produced, using a kriging algorithm of the concentrations in respect to their geographical coordinates, to estimate a spatial distribution in an area comprising all the stations.

\section{Results and Discussion}

3.1. Trend Line Analysis. To analyze CO concentration evolution, the first aspect is the trend. To help the analysis of these results, the stations are divided into 4 groups. The first one (Group 1 in Table 2) comprises the longer series, with more than 13 years of measurements; the second one (Group 2 in Table 2) comprises series that begin in 1996 and end before 2009; the third (Group 3 in Table 2) comprises series that begin after 2001 and have over 8 years of measurements; and the fourth (Group 4 in Table 2) comprises more recent series. CA and SP11 were not considered because their series are shorter than 2 years. All the stations in groups 1 to 3 have rejected the null hypothesis with a confidence interval of $95 \%$, indicating that the analysis is 95\% confident that the $R^{2}$ value for the exponential fit is accurate.

Group 1 presented larger values for $R^{2}$, indicating that most of the variations observed in the series can be explained by the trend line and, consequently, that the impact of the PROCONVE implementation was more effective for these series. All series in Group 1, except OS station, were better fitted by a logarithmic function with a negative inclination. For example, Figure 2 shows the best fit for SP4, suggesting that the concentration of $\mathrm{CO}$ decreased drastically at the beginning of the series and then tended to stabilize (Figure 2(a)). The exponential fit does not present a significantly different coefficient of determination and provides the increasing or decreasing rates in percentages per month. The largest decreasing rate for this group $(\sim 0.7 \%$ per month) is found for SP7, which is located in the central area of the city. This rate is not very different from other stations of this group located near the center of Sao Paulo city, where traffic is usually heavy and the restriction police is in effect (e.g., the rate for stations SP1 and SP4 is 6\% per month). 


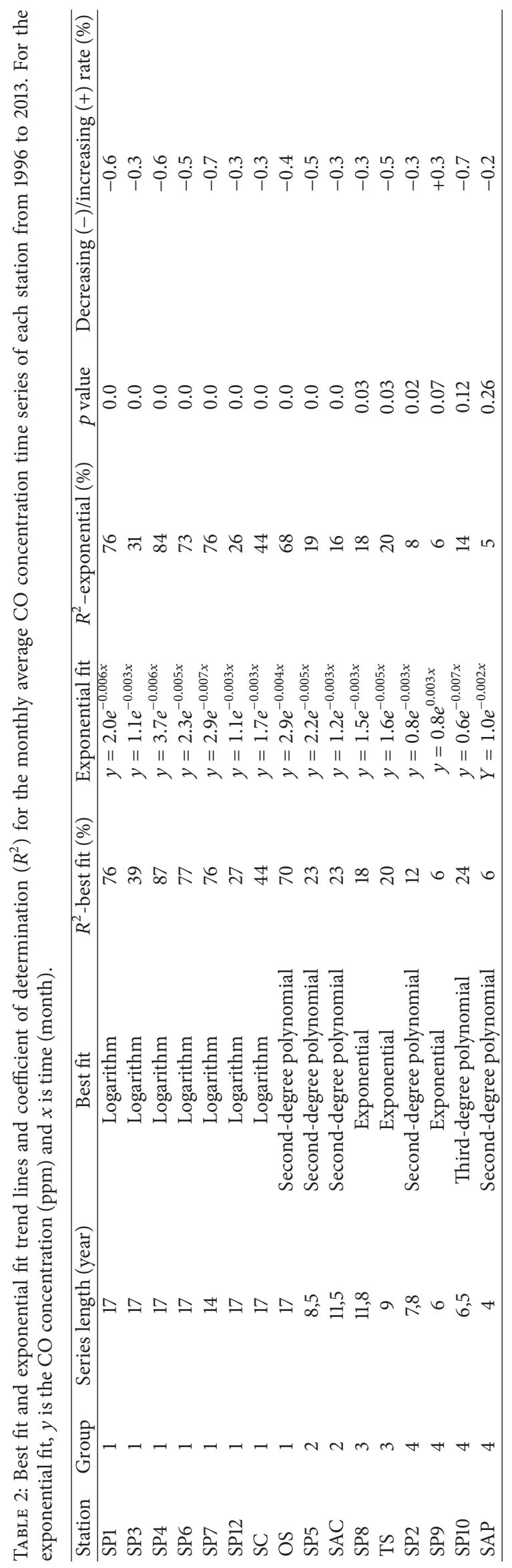


Only OS station time series presented a polynomial function as the best fit; however $R^{2}$ does not differ much from the exponential fit coefficient. Therefore, it is possible to assume that the OS station series indicates a decrease rate of $0.4 \%$ per month.

The series in Group 2, SAC and SP5, were better fitted to a polynomial function and the exponential fit presents a decreasing rate of 0.3 and $0.5 \%$ per month, respectively. SP8 and TS (Group 3) time series were fitted to exponential curves, with decreasing rates of 0.3 and $0.5 \%$ per month, respectively. However, only a small percentage of the variation of the series may be explained by the curves for groups 2 and 3.

Group 4 presents a tendency of increase of CO concentration by the end of the series; however they have small values for the coefficient of determination and only station SP2 rejects the null hypothesis (with a confidence interval of $95 \%$ ), meaning that they may have no tendency at all, as illustrated by SP9 series (Figure 2(b)). The lack of tendency for this group may be a result of the length of the series, where other variations (seasonal) have more relative importance or may indicate again a stabilizing tendency.

To validate the analysis, the same process was performed using yearly averages (not shown here). The results corroborated the values presented in Table 2 , in the form of the trend line and in the equivalent decreasing/increasing rates. The results are also equivalent to the ones obtained by Carvalho et al. [8]; however, as the authors only performed a linear regression, the changes in the decreasing rate (greater in 1996 and smaller lately) are averaged and thus neglected.

It is noticeable that the trend lines for older/longer series are strongly related to the effect of emission control policies, particularly PROCONVE. The implementation of the program included adequacy of catalysts, improvement of mixture formation, usage of electronic fuel injection, and electronic control module, associated with the renewal of the vehicular fleet, and has successfully mitigated the air pollution caused by CO. Nevertheless, during the series period, another public policy is in effect: the restriction of $20 \%$ of the vehicular fleet (by the last digit of the car plate) in the extended central area of the city of Sao Paulo (thick black line in Figure 1) during rush hours on weekdays. Although it is difficult to separate the effect of different policies, the stations that have the oldest records (Groups 1 and 2 in Table 2) and that are inside the restriction zone (SP1, SP4, SP5, SP6, and SP7, Table 1) present a larger decreasing tendency (from 0.5 to $0.7 \%$ per month) than the ones that have no restriction (SP12, SAC, SC, and OS-decreasing tendency from 0.3 to $0.4 \%$ per month). The exception is station SP3 that is located inside a park. This may suggest that the local policy helped in decreasing CO concentrations locally, particularly when added to the PROCONVE program.

3.2. Periodogram Analysis. Since the trend line represents only part of the time evolution of CO concentration, other variations must be investigated. As previously explained, the series of hourly averages of $\mathrm{CO}$ concentration for each station were prepared to be used by a periodogram analysis. The

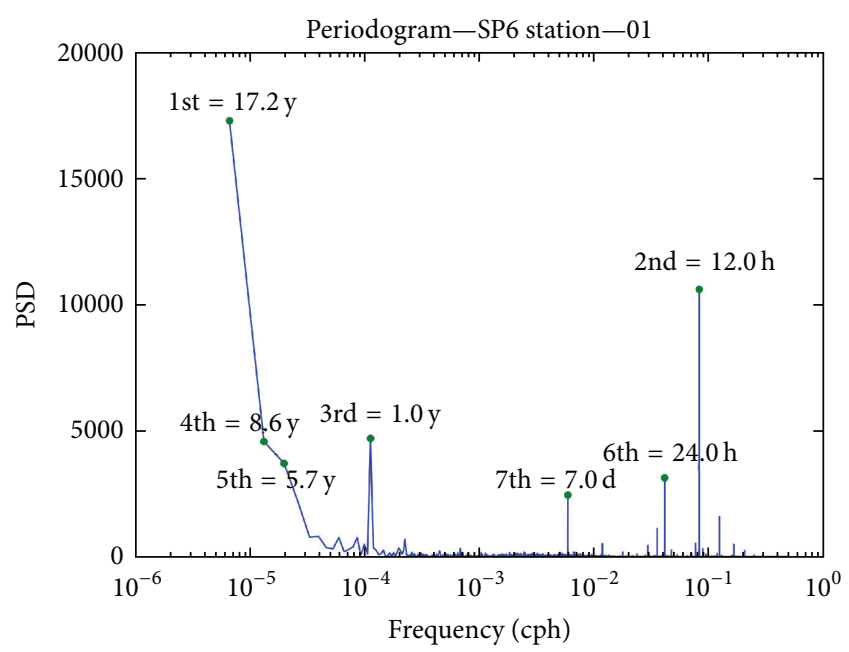

FIGURE 3: Periodogram for SP6 station hourly average time series. The 7 peaks with highest spectral density represent the periods: 17.2 years, 12 hours, 1 year, 8.6 years, 5.7 years, 24 hours, and 7 days. The frequency unit is cycles per hour $(\mathrm{CPH})$ and PSD is the power spectrum density.

periodogram for SP6 station (Figure 3), for example, shows peaks corresponding to 17.1 years, 12 hours, 1 year, 8.6 years, 5.7 years, 24 hours, and 7 days.

The 7 highest peaks for each series were analyzed and showed that the 24-hour, 12-hour, and 1-year periods are the most frequent of all values. As expected, the 1-year period is not present at shorter series. Therefore, the CO concentration evolution has strong semidiurnal, diurnal, and seasonal cycles. Some of the longest series present a period equal to their length, suggesting a strong tendency in time, related to the decreasing trend already analyzed. Other periods that appeared more than once in the analysis are 6 months (seasonal behavior) and 7 days (weekly traffic pattern).

The diurnal and annual cycles of $\mathrm{CO}$ concentration were then calculated by averaging $\mathrm{CO}$ concentrations for each year (considering all the stations) by hour (diurnal) and month (annual). Figure 4 shows these averages, considering only the oldest and the most recent years that have a representative data set (1997 and 2012). Even though in 1997 the average $\mathrm{CO}$ concentration is approximately twice the concentration in 2012, there are some similarities. The diurnal pattern (Figure 4(a)) shows two peaks that represent the two traffic rush hours (maximums at $0800 \mathrm{LT}$ and $2000 \mathrm{LT}$ ) and an evolution that corresponds to the PBL development. These two peaks explain why a 12-hour period was found in the spectral analysis. At $0600 \mathrm{LT}$ traffic and concentration start to increase until $0800 \mathrm{LT}$. After that even though traffic is still heavy, the PBL grows and air is entrained from aloft, causing $\mathrm{CO}$ concentration to decrease. After a minimum (at 1400 LT in 1997 and 1600 LT in 2012), the concentration increases again, related to the increase in traffic and the beginning of the evening rush hour, peaking at $2000 \mathrm{LT}$, when the PBL has already collapsed (Figure 4(a)). After this hour, an important change is observed between 1997 and 2012: 


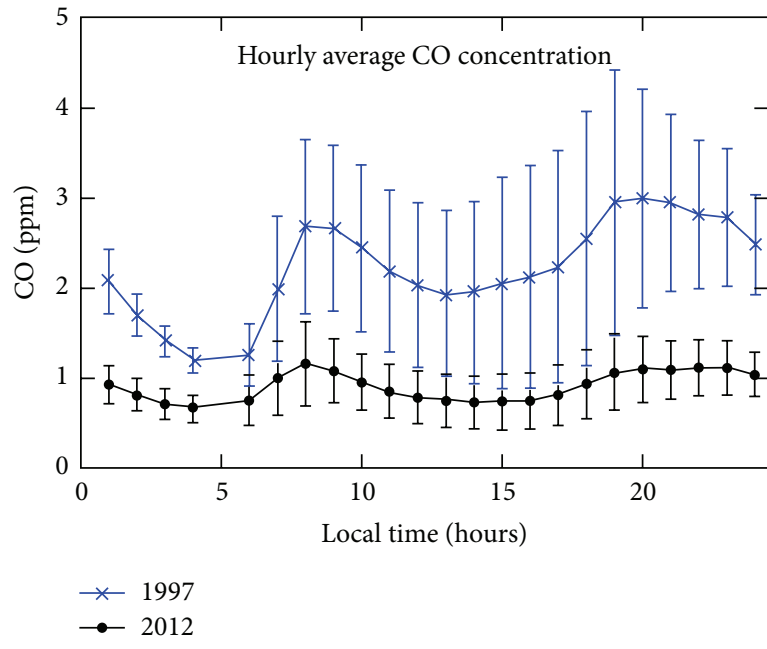

(a)

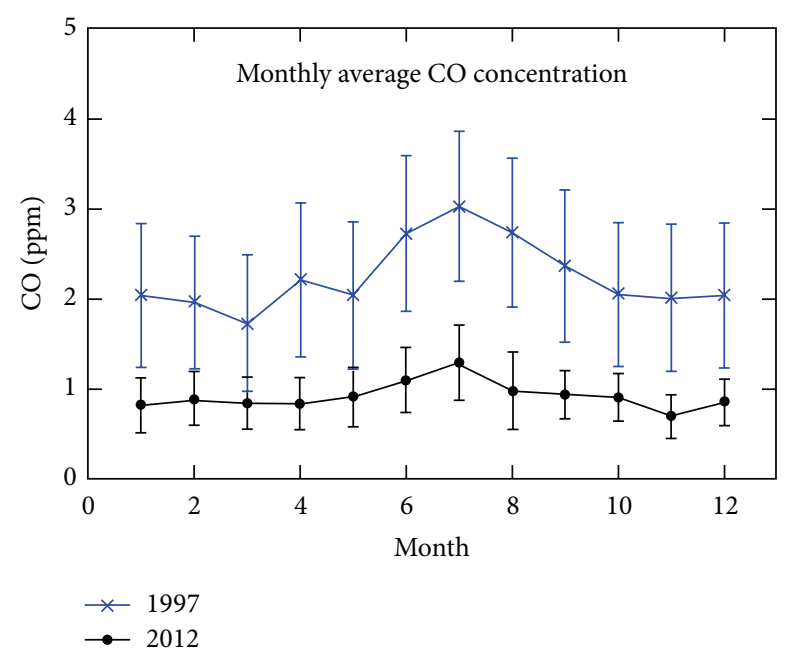

(b)

FIGURE 4: (a) Hourly and (b) monthly averages of CO concentration for the MRSP for the years 1997 (blue) and 2012 (black). 10 stations were considered for 1997 and 14 stations for 2012. Error bars represent the standard deviation.

while in 1997 the evening peak has a higher value than the morning peak and decreases immediately after 2000 LT, in 2012 the concentration is almost the same from 2000 LT to $2300 \mathrm{LT}$ and it is smaller than for the same year morning peak, showing an expansion of the evening rush hour. In fact, this trend is observed through the years (not shown) and the difference between the 1900 LT average and 2300 LT average decreased in time from a maximum value in 1999 of $0.3 \mathrm{ppm}$ to $0.05 \mathrm{ppm}$ in 2012 . Although it is difficult to identify the cause of this change, it may be influenced by the restriction policy that took effect in October 1997 (restriction during rush hours in the central part of the city) and by a change in driving behavior, showing that traffic has increased at night lately or that drivers may prefer to wait until after the restriction period (2000 LT) to drive home. Stations SP1, SP4, and SP6 seem to be causing this change, since they have changed their pattern accordingly (not shown here), and they are located inside the restriction zone. Another factor to consider is that the number of vehicles has significantly increased and traffic conditions have deteriorated, increasing emission of pollutants while vehicles are stopped in traffic. After 2300 LT, traffic decreases and so does the $\mathrm{CO}$ concentration due to the pollutant transport and dispersion mechanisms. Another interesting observation is related to the standard deviation, represented by the vertical line over each average. This deviation is caused by differences in the meteorological conditions (the average includes different seasons) and emission patterns (weekends, holidays, school breaks, etc.). Its value has decreased from 1997 to 2012, when the averages also decreased, except between 0100 and 0400 LT, when emission is much smaller and meteorological conditions and traffic patterns play a minor role, as the PBL is usually stable and its height is shallower than during daytime.

The annual pattern (Figure 4(b)) presents higher concentrations during austral winter (peaking in July), for both periods, and lower concentrations for the other seasons, with the lowest monthly average during austral autumn (March) in 1997 and austral spring (November) in 2012. The difference in the month of the minimum concentration suggests different atmospheric conditions. The standard deviation has also decreased in time, showing less variability (diurnal cycle, Figure 4(a)) around the average.

3.3. Correlation to Meteorological Variables. To evaluate the impact of meteorological conditions on the time evolution of $\mathrm{CO}$ concentration, the influence of the meteorological variables was analyzed by calculating the correlation between the $\mathrm{CO}$ concentration and each of the following variables: air temperature, wind speed, and relative humidity. The correlation was calculated using monthly averages of $\mathrm{CO}$ concentration and of each meteorological variable. The hypothesis test was also calculated (Table 3). Among 7 stations that measured relative humidity, only 2 rejected the null hypothesis, indicating that the analysis is $95 \%$ confident that the coefficient $(r)$ for these stations has statistical significance. The values of $r$ indicate only a weak inverse correlation, suggesting that the $\mathrm{CO}$ concentration is lower when the humidity is higher. This pattern is related to the seasonal cycle of CO that has higher monthly averaged concentrations during winter, when humidity in Sao Paulo is lower, and lower concentrations during summer, when humidity is higher. Another important phenomenon in Sao Paulo is the sea breeze that reaches the city $50 \%$ of the days of the year. The sea breeze usually brings moister, cooler, and less polluted air and may contribute to this inverse correlation.

When correlating the CO concentration to the air temperature, 5 out of 7 stations rejected the null hypothesis, three of them presenting moderate inverse correlation (CA, SP3, and SP8), and two presenting weak inverse correlations (SP1 and SC), indicating that $\mathrm{CO}$ concentration decreases when the temperature increases. This pattern is again related to the seasonal cycle of $\mathrm{CO}$ concentrations (higher during winter 
TABLE 3: Correlation coefficient $(r)$ between monthly averages of each meteorological variable and CO concentration and results for the hypothesis test.

\begin{tabular}{|c|c|c|c|c|c|c|}
\hline \multirow{2}{*}{ Station } & \multicolumn{2}{|c|}{ Relative humidity } & \multicolumn{2}{|c|}{ Temperature } & \multicolumn{2}{|c|}{ Wind speed } \\
\hline & $r$ & $p$ value & $r$ & $p$ value & $r$ & $p$ value \\
\hline SP1 & -0.267 & 0.01 & -0.28 & 0.01 & -0.187 & 0.05 \\
\hline SP2 & - & - & - & - & 0.213 & 0.15 \\
\hline SP3 & -0.108 & 0.20 & -0.601 & 0.0 & -0.375 & 0.0 \\
\hline SP5 & - & - & - & - & -0.325 & 0.01 \\
\hline SP8 & -0.098 & 0.40 & -0.527 & 0.0 & -0.376 & 0.0 \\
\hline SP9 & -0.438 & 0.09 & -0.116 & 0.55 & - & - \\
\hline SP11 & -0.198 & 0.56 & -0.139 & 0.68 & -0.772 & 0.01 \\
\hline SP12 & - & - & - & - & -0.154 & 0.04 \\
\hline OS & - & - & - & - & -0.082 & 0.25 \\
\hline SC & -0.36 & 0.0 & -0.352 & 0.0 & -0.071 & 0.39 \\
\hline $\mathrm{CA}$ & 0.011 & 0.97 & -0.659 & 0.01 & -0.695 & 0.0 \\
\hline SAC & - & - & - & - & -0.178 & 0.09 \\
\hline
\end{tabular}

TABLE 4: Regression equation for CO concentration (CO), temperature $(T)$, relative humidity $(R H)$, and wind speed $(W) . R^{2}$ and $p$ value refer to the regression equation. An alternative regression equation is calculated when a variable coefficient does not have a $95 \%$ confidence interval.

\begin{tabular}{|c|c|c|c|c|c|c|}
\hline Station & Regression equation & $R^{2}(\%)$ & $p$ value & Alternative regression equation & $R^{2}(\%)$ & $p$ value \\
\hline SP1 & $\mathrm{CO}=4.703-0.0347 \mathrm{~T}-0.0242 R H-0.305 \mathrm{~W}$ & 20.0 & 0.0 & $\mathrm{CO}=4.547-0.0376 T-0.0276 R H$ & 17.8 & 0.0 \\
\hline SP3 & $\mathrm{CO}=3.029-0.0703 \mathrm{~T}-0.0052 R H-0.2683 \mathrm{~W}$ & 41.1 & 0.0 & $\mathrm{CO}=2.626-0.0724 T-0.239 W$ & 40.0 & 0.0 \\
\hline SP8 & $\mathrm{CO}=5.765-0.0746 T-0.0292 R H-0.604 W$ & 49.9 & 0.0 & & & \\
\hline SP11 & $\mathrm{CO}=2.779+0.0265 T-0.011 R H-0.813 W$ & 87.3 & 0.002 & & & \\
\hline CA & $\mathrm{CO}=2.705-0.0258 \mathrm{~T}-0.0083 R H-0.3864 \mathrm{~W}$ & 81.9 & 0.0 & & & \\
\hline SC & $\mathrm{CO}=5.297-0.0663 T-0.0305 R H-0.089 \mathrm{~W}$ & 35.7 & 0.0 & $\mathrm{CO}=5.163-0.0676 T-0.0302 R H$ & 35.5 & 0.0 \\
\hline
\end{tabular}

and lower during summer). However, it may also be related to the PBL development, since colder months tend to have lower PBL heights $[16,19]$.

For the wind speed, 11 stations were analyzed and only 4 fail to reject the null hypothesis. Most stations presented weak inverse correlation, except SP11 and CA that presented moderate to strong inverse correlation. These stations also presented a relatively higher averaged wind speed (not shown here) than the others (approximately $2 \mathrm{~ms}^{-1}$ ), indicating that the wind is more correlated to $\mathrm{CO}$ when its velocity is higher. High wind speeds enhance the turbulence and increase the dispersion and transport of $\mathrm{CO}$, decreasing its concentration. When the wind speed is low, the $\mathrm{CO}$ emitted tends to concentrate near its sources.

A multivariate analysis was then performed to investigate the relative effect of temperature, relative humidity, and wind velocity on $\mathrm{CO}$ concentration. Table 4 shows the regression equation, the coefficient of determination $\left(R^{2}\right)$, and the $p$ value of the equation. $R^{2}$ is higher for stations with shorter and more recent time series (CA and SP11), probably because these series do not have a significant decrease in concentration caused by the PROCONVE program. Stations SP1, SP3, and SC presented $p$ values greater than 0.05 for one of the meteorological variables (wind speed, relative humidity, and wind speed, respectively-not shown here) and alternative regression equations were calculated without these variables.
Most of the coefficients are negative, suggesting that they are inversely correlated to CO concentration. Again, the only station that has a positive coefficient for temperature is SP11, indicating that the other stations present a positive correlation between temperature and relative humidity when using monthly averages. The wind speed has higher coefficient values, suggesting that it presents the greatest contribution to $\mathrm{CO}$ concentration. The multivariate analysis corroborates the previous correlation analysis. The meteorological conditions cannot be singly used to explain or forecast air quality conditions. They help, however, to understand temporal and spatial differences when combined with emission patterns.

3.4. Spatial Distribution. Since there are significant differences among the stations regarding temporal evolutions and correlation to meteorological variables, a spatial analysis was performed using annual averages. Figure 5 presents the spatial distribution of CO concentration annual average for each station in the MRSP for 3 years: 1997, 2008, and 2012. These years were chosen because 1997 is the first year that has a complete series, 2012 is the last year with a complete series, and 2008 is the least recent year with the greater number of stations. An overall decrease of the concentration with time is noticeable for almost all stations.

Annual averages do not follow a spatial pattern. For example, stations SP3 and SP9 are farther apart than SP3 and 


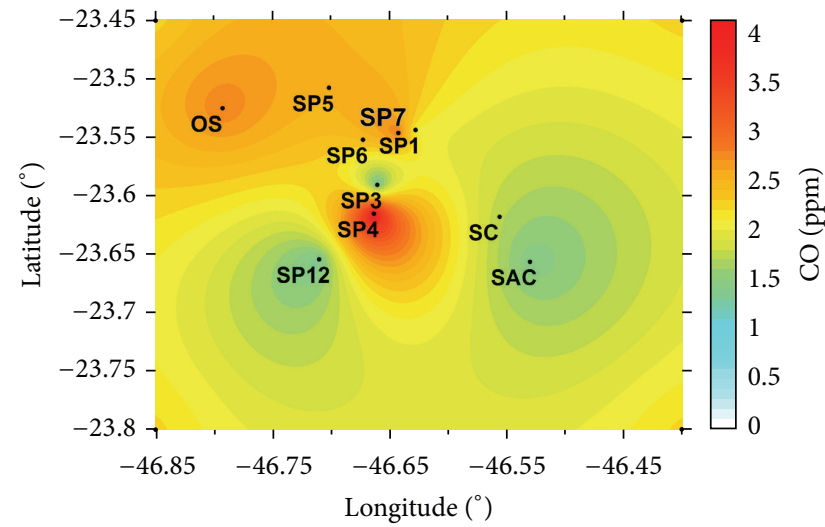

(a)

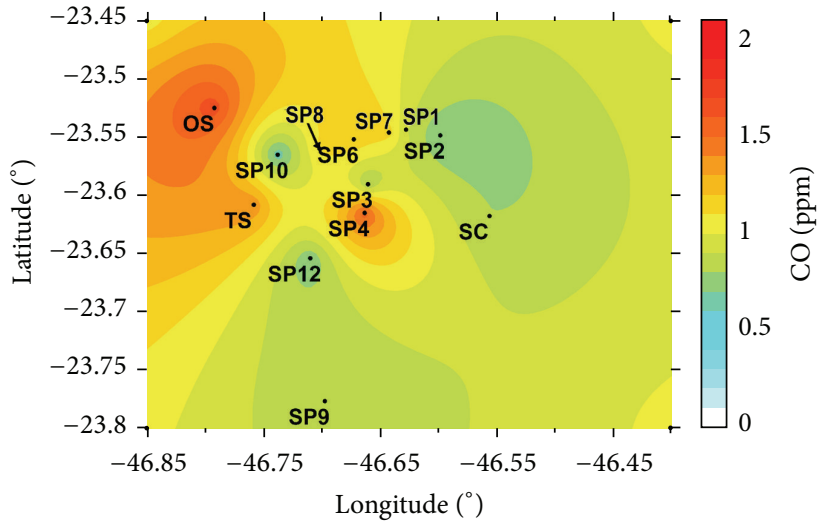

(b)

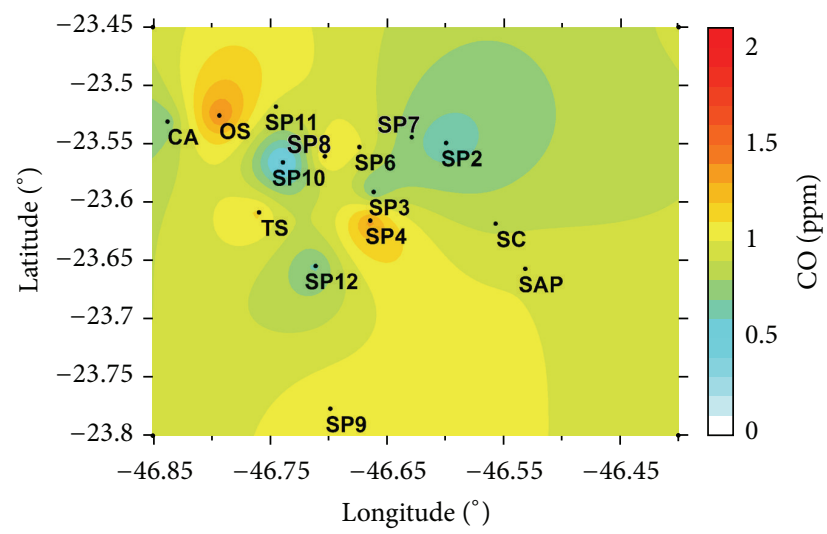

(c)

FIGURE 5: Spatial distribution of the annual average of CO concentration during (a) 1997, (b) 2008, and (c) 2012. CO concentration is in ppm. Contour interval is $0.2 \mathrm{ppm}$. Obs.: Color scale is different between (a) and (b, c).
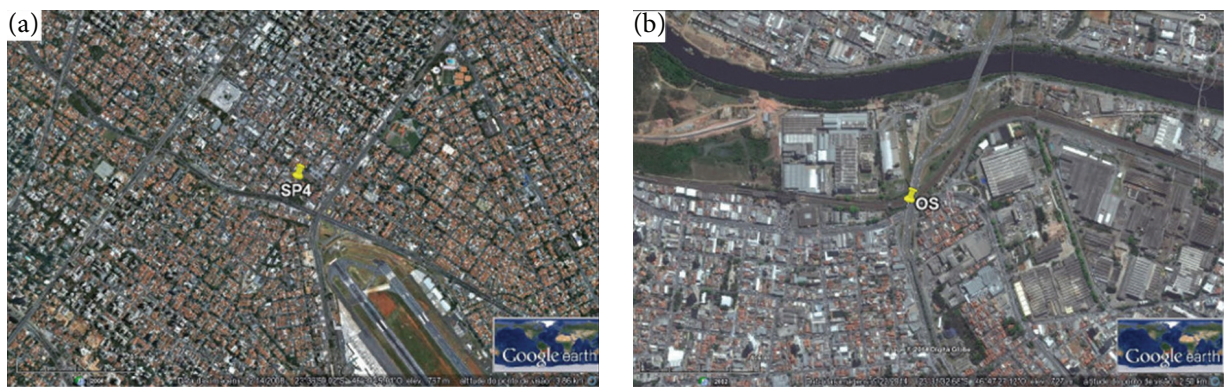

FIGURE 6: Image of stations. (a) SP4, the airport is at the lower right corner (source: Google Earth, 14 Dec 2008, 08 Dec 2014 ) and (b) OS (source: Google Earth, 22 Sep 2014, 08 Dec 2014).

SP4 and yet the former stations have similar averages, while SP4 has the highest average among them. These differences seem to be related to traffic intensity and proximity, since the correlation between each meteorological variable and $\mathrm{CO}$ concentration is mostly weak or nonexistent and greater scale meteorological phenomena, such as cold fronts, sea breeze, and synoptic events, are expected to affect the whole MRSP similarly. Some stations present the highest values throughout the years (SP4 and OS) while some others sustain the lowest values (SP12, SP3, SP2, and SP10). A visual analysis of the stations surrounding areas using satellite images indicates that the stations with high annual averages are located near heavy traffic highways and scarcely vegetated areas (Figure 6 in the Appendix). Besides that, SP4 is near an airport that has a daily average of landings and takeoffs equal to 585 [24]. On the other hand, the stations with low annual averages are located inside areas with less traffic and more vegetation, as parks, university campus, or sports club (Figure 7 in the Appendix). SP9 shows a slight increase of the annual average from 2008 to 2012 (the station was not operating in 1997), 

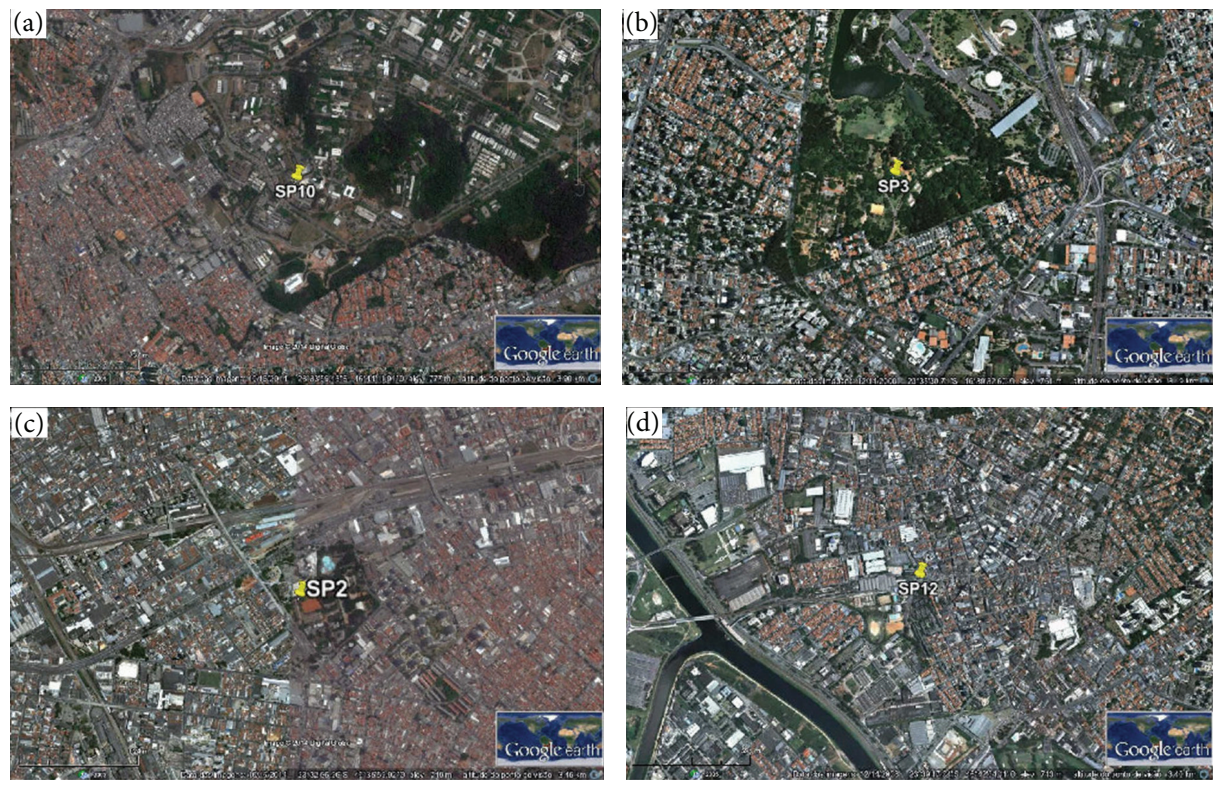

Figure 7: Image of stations. (a) SP10 (source: Google Earth, 16 Oct 2014, 08 Dec 2014), (b) SP3 (source: Google Earth, 14 Dec 2008,08 Dec 2014), (c) SP2 (source: Google Earth, 16 Oct 2014, 08 Dec 2014), and (d) SP12 (source: Google Earth, 14 Dec 2008, 08 Dec 2014 ).

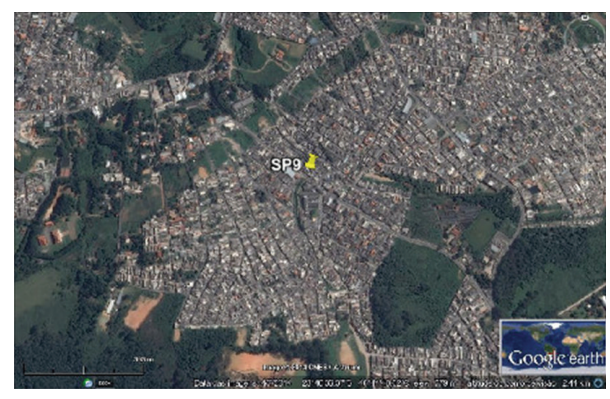

Figure 8: Image of station SP9 (source: Google Earth, 04 Jul 2014, 08 Dec 2014).

already pointed by the trend line analysis. The cause of this tendency may be an increase in emissions due to urbanization and/or increase of local traffic, since the station is located near a highway, even though there are some vegetated areas nearby (Figure 8 in the Appendix).

Figure 5 also shows that the spatial variability of $\mathrm{CO}$ concentration is still high, since the highest annual average in 2012 (1.4 ppm-OS station) is three and a half times greater than the lowest annual average (0.4-SP10 station). This result indicates which are the areas that impose greater challenges for mitigation and planning policies. It may also suggest that other cities (e.g., Osasco-OS station) may benefit from implementing some kind of traffic restriction as Sao Paulo did.

The observed spatial distribution of the $\mathrm{CO}$ concentration and the complexity of the urban mosaic found at the MRSP suggest that there are spatial details that are missed by the present monitoring network, particularly considering the scarcity of stations in the east and south zones of the city.
Hence, the use of a numerical model may be the solution to further investigate the patterns of spatial distribution and temporal evolution of CO concentration at the MRSP. The present analysis shows that the local characteristics of each station must be considered when comparing results from numerical models to the observations, or when using the recorded data for decision-making processes. It also indicates that a careful representation of emission patterns, land use types, and spatial distribution of sources are key in studying and modeling air quality in Sao Paulo.

\section{Conclusions}

In this work, 17 years of measurements taken by 18 air quality monitoring stations in the MRSP were analyzed in respect of temporal evolution and spatial distribution, aiming to present a thorough investigation about the temporal trends and cycles of $\mathrm{CO}$ concentration and their relationship to meteorological conditions and to local factors, to provide a better understanding of $\mathrm{CO}$ concentration patterns for modeling and policy studies.

Although it is difficult to link the CO concentration tendency to the public policies, the temporal evolution and the periodogram analysis pointed out that the federal control program (PROCONVE) was able to decrease the concentration of this pollutant at rates from 0.7 to $0.3 \%$ per month from 1996 to 2013. This program was probably aided by a local policy in the city of Sao Paulo that prevented the traffic of $20 \%$ of the vehicles in the central area of the city, during rush hours in weekdays. The vehicular inspection, implemented in 2009, may have also helped the decreasing tendency of later years, although it is not possible to determine its exact effect by the present analysis. Recently, the concentrations presented a 
stabilizing (or even localized increasing) tendency, probably caused by the increasing amount of vehicles, suggesting that other forms of public policies must be implemented, following recent attempts, that aim to reduce private vehicular transport and increase the use of public transportation, as well as establishing smaller emission factors for pollutants.

The periodogram analysis shows that the most important periods of variation of $\mathrm{CO}$ concentration are 1 day, 12 hours, and 1 year, suggesting that $\mathrm{CO}$ follows a diurnal and an annual cycle. Both cycles present an influence of the decreasing tendency mentioned above; however the diurnal cycle has evolved to a different pattern. The evening rush hour seems to be extended, indicating a change in driving behavior, caused by the restriction period (from $1700 \mathrm{LT}$ to $2000 \mathrm{LT}$ ), particularly for stations located inside or near the restriction zone. For modeling purposes, a weekly cycle may also be considered. These results, combined with the investigation of the correlation of the $\mathrm{CO}$ to humidity, temperature, and wind speed, suggest that $\mathrm{CO}$ concentration is greatly influenced by traffic emissions and PBL development, because when the vertical mixing is expected to be higher (during the afternoon and during spring/summer months), CO concentrations are lower, and when the PBL is less developed (during mornings and after sunset, particularly during winter), the $\mathrm{CO}$ concentrations are higher. Wind speed was the variable that presented higher correlation to $\mathrm{CO}$ concentration, particularly for stations with higher averaged wind speed.

The spatial distribution reinforces the dependence of $\mathrm{CO}$ concentrations on traffic emissions and local effects, like presence of vegetation, proximity to heavy traffic, facilities, and so forth. Some areas, such as SP9 station, indicate the necessity of mitigation policies. Depending on the causes for the increase in CO concentration, the actions may range from improving public transport infrastructure to developing educational programs that encourage the use of public transportation. This result indicates that a numerical study, through an appropriately detailed urban model, could enhance the understanding of $\mathrm{CO}$ spatial distribution in the MRSP. It also suggests that the characteristics of each station need to be considered when analyzing these data, either for model validation or for decision-making purposes.

The present work has provided a complete analysis of the temporal and spatial evolution of CO in Sao Paulo that can be used as verification for modeling studies and as basis for policy efficiency studies and decision-making processes. The analysis provides evidence of changes in CO concentration tendency and diurnal cycle and considerable spatial variability within the metropolitan area. However, more investigation is needed to establish the relative contribution of local characteristics, meteorological conditions, local and federal public policies, and changes in driving behavior in determining the evolution of $\mathrm{CO}$ temporal evolution and spatial distribution in the MRSP.

\section{Appendix}

See Figures 6, 7, and 8.

\section{Competing Interests}

The authors declare that there are no competing interests regarding the publication of this paper.

\section{Acknowledgments}

The authors would like to thank the Fundação de Amparo a Pesquisa do Estado de Sao Paulo (FAPESP), Grant no. 2014/04372-2, the Conselho Nacional de Desenvolvimento Cientifico e Tecnologico (CNPq), Grant no. 443029/2014-8, and the University of Sao Paulo for funding this work and the Environmental Agency of Sao Paulo (CETESB) for providing the data.

\section{References}

[1] WHO, "Air quality deteriorating in many of the world's cities," WHO Press Release, http://www.who.int/mediacentre/news/ releases/2014/air-quality/en/.

[2] M. Jerrett, R. T. Burnett, C. A. Pope III et al., "Long-term ozone exposure and mortality," The New England Journal of Medicine, vol. 360, no. 11, pp. 1085-1095, 2009.

[3] C. A. Pope III and D. W. Dockery, "Health effects of fine particulate air pollution: lines that connect," Journal of the Air \& Waste Management Association, vol. 56, no. 6, pp. 709-742, 2006.

[4] D. Brugge, J. L. Durant, and C. Rioux, "Near-highway pollutants in motor vehicle exhaust: a review of epidemiologic evidence of cardiac and pulmonary health risks," Environmental Health: A Global Access Science Source, vol. 6, article 23, 2007.

[5] A. Peters, A. Döring, H.-E. Wichmann, and W. Koenig, "Increased plasma viscosity during an air pollution episode: a link to mortality?” The Lancet, vol. 349, no. 9065, pp. 1582-1587, 1997.

[6] R. M. de Miranda, M. de Fatima Andrade, A. Fornaro, R. Astolfo, P. A. de Andre, and P. Saldiva, "Urban air pollution: a representative survey of PM 2.5 mass concentrations in six Brazilian cities," Air Quality, Atmosphere and Health, vol. 5, no. 1, pp. 63-77, 2012.

[7] A. P. De Oliveira, A. J. Machado, J. F. Escobedo, and J. Soares, "Diurnal evolution of solar radiation at the surface in the city of São Paulo: seasonal variation and modeling," Theoretical and Applied Climatology, vol. 71, no. 3-4, pp. 231-249, 2002.

[8] V. S. B. Carvalho, E. D. Freitas, L. D. Martins, J. A. Martins, C. R. Mazzoli, and M. F. de Andrade, "Air quality status and trends over the Metropolitan Area of Sao Paulo, Brazil as a result of emission control policies," Environmental Science and Policy, vol. 47, pp. 68-79, 2015.

[9] CETESB, Vehicular Emissions in Sao Paulo State, 2014, CETESB, 2015.

[10] G. I. Gorchakov, E. G. Semoutnikova, E. S. Baikova, and A. V. Karpov, "The weekly cycle of diurnal variation of the carbon monoxide concentration in the surface and boundary layers of the urban atmosphere," Doklady Earth Sciences, vol. 455, no. 2, pp. 425-429, 2014.

[11] A. M. Zvyagintev, I. N. Kuznetsova, O. A. Tarasova, and I. Y. Shalygina, "Variations in the concentrations of main air pollutants in London," Atmospheric and Oceanic Optics, vol. 27, no. 5, pp. 417-427, 2014. 
[12] B. T. Richman, "Air pollution in the world's megacities," Environment, vol. 36, no. 2, pp. 2-13, 1994.

[13] V. F. Kramar, E. Baykova, M. Kallistratova, R. Kouznetsov, and S. Kulichkov, "Ground-based remote sensing of the ABL structure in Moscow and its use to estimate pollutant surface emission rates," Journal of Applied Meteorology and Climatology, vol. 53, no. 5, pp. 1272-1281, 2014.

[14] Brasil, Resolução CONAMA no 18, 6 May 1986, Diario Oficial da Uniao; 17 June 1986 (Portuguese), http://www.mma.gov.br/ port/conama/res/res86/res1886.html.

[15] P. J. Pérez-Martínez, M. F. Andrade, and R. M. de Miranda, "Traffic-related air quality trends in São Paulo, Brazil," Journal of Geophysical Research: Atmospheres, vol. 120, no. 12, pp. 62906304, 2015.

[16] CETESB, Vehicular Emissions in Sao Paulo State, 2013, CETESB, 2014.

[17] CETSP, “CET-Companhia de Engenharia de Trafego," 2015, http://www.cetsp.com.br/consultas/rodizio-municipal.aspx.

[18] Planeja Sampa, "Planeja Sampa," 2014, http://planejasampa.prefeitura.sp.gov.br/.

[19] CETESB, Air Quality in Sao Paulo State, 2013, CETESB, 2014.

[20] M. D. Wilbert, A. L. M. Serrano, R. S. Gonçalves, and L. S. Alves, "Tax reduction on industrialized products and its effect on car sales in Brazil: an analysis of the period 2006 to 2013," Revista Contemporânea de Contabilidade, vol. 11, no. 24, pp. 107-124, 2014.

[21] P. C. Novelli, K. A. Masarie, and P. M. Lang, "Distributions and recent changes of carbon monoxide in the lower troposphere," Journal of Geophysical Research: Atmospheres, vol. 103, no. 15, pp. 19015-19033, 1998.

[22] “Qualar.cetesb.sp.gov.br," Serviços-CETESB, 2014, http://qualar .cetesb.sp.gov.br/qualar/home.do.

[23] R. T. Lacoss, "Data adaptive spectral analysis methods," Geophysics, vol. 36, no. 4, pp. 661-675, 1971.

[24] Aeroporto de Sao Paulo/Congonhas-Infraero, 2015, https:// www.infraero.gov.br/index.php/aeroportos/sao-paulo/aeroporto-de-sao-paulo-congonhas.html. 

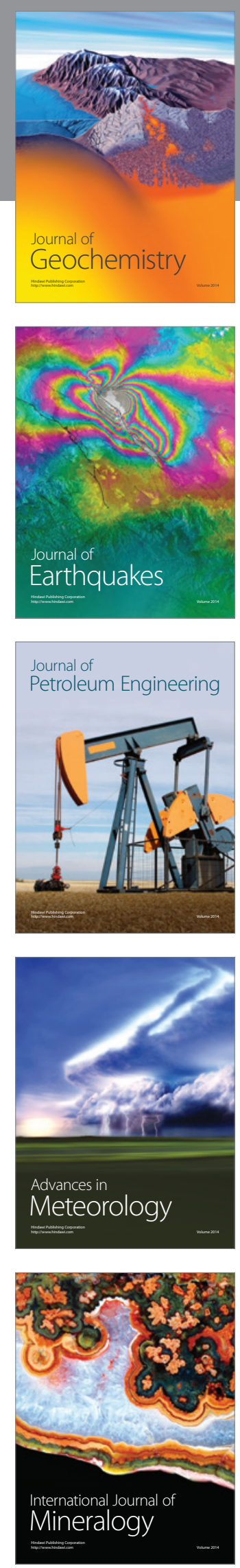
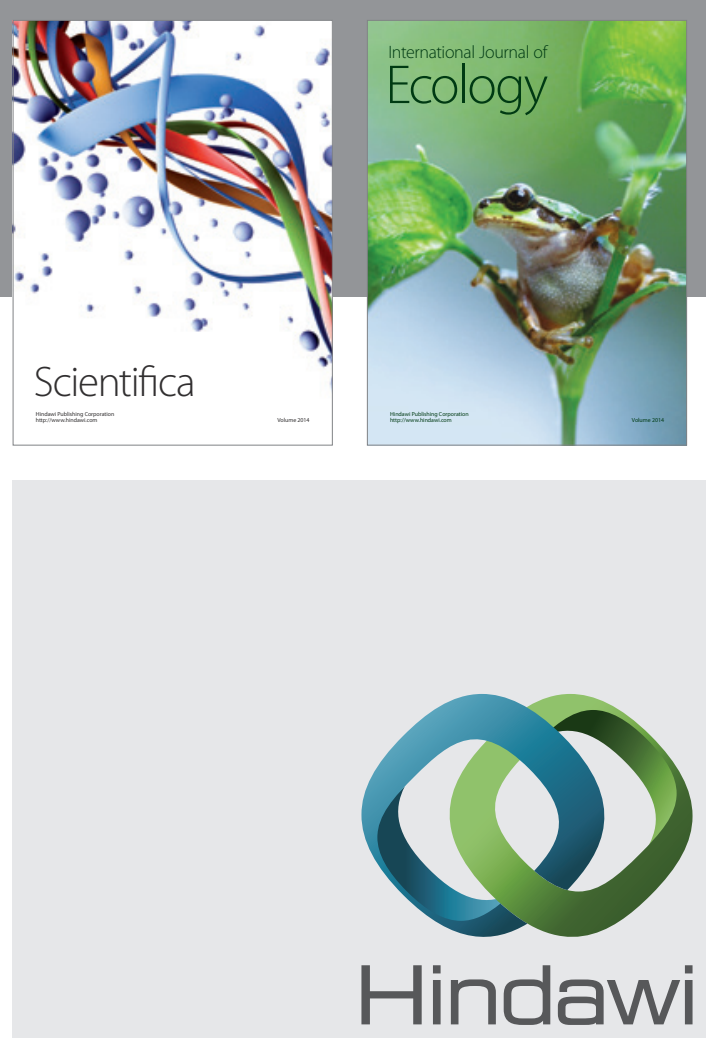

Submit your manuscripts at

http://www.hindawi.com
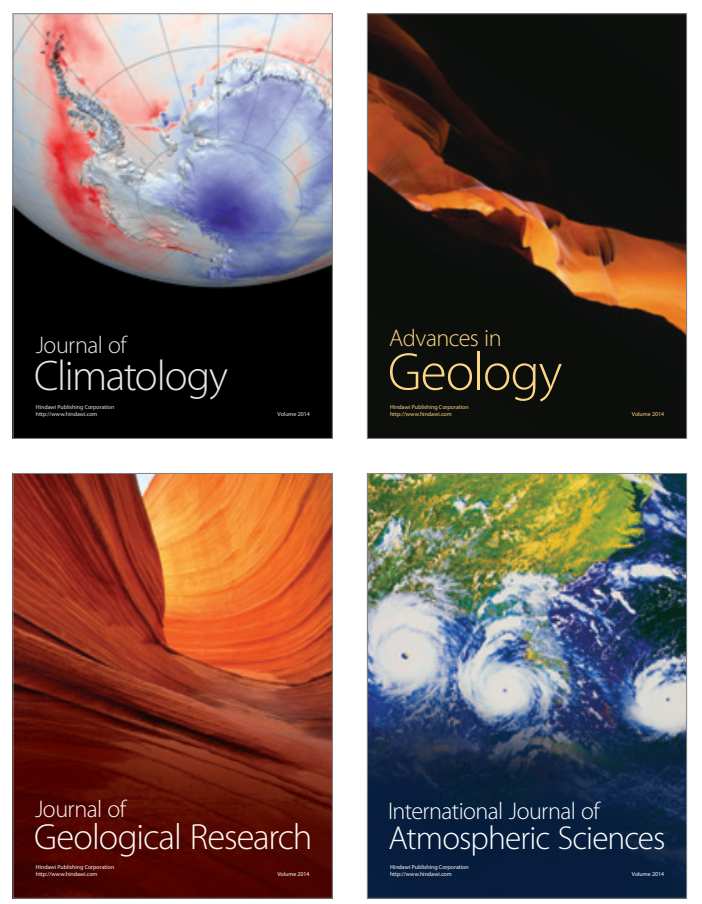

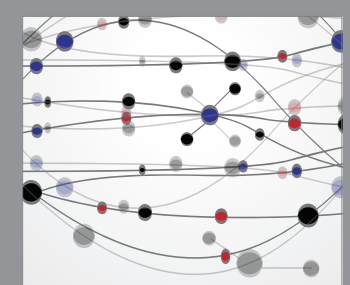

The Scientific

\section{World Journal}
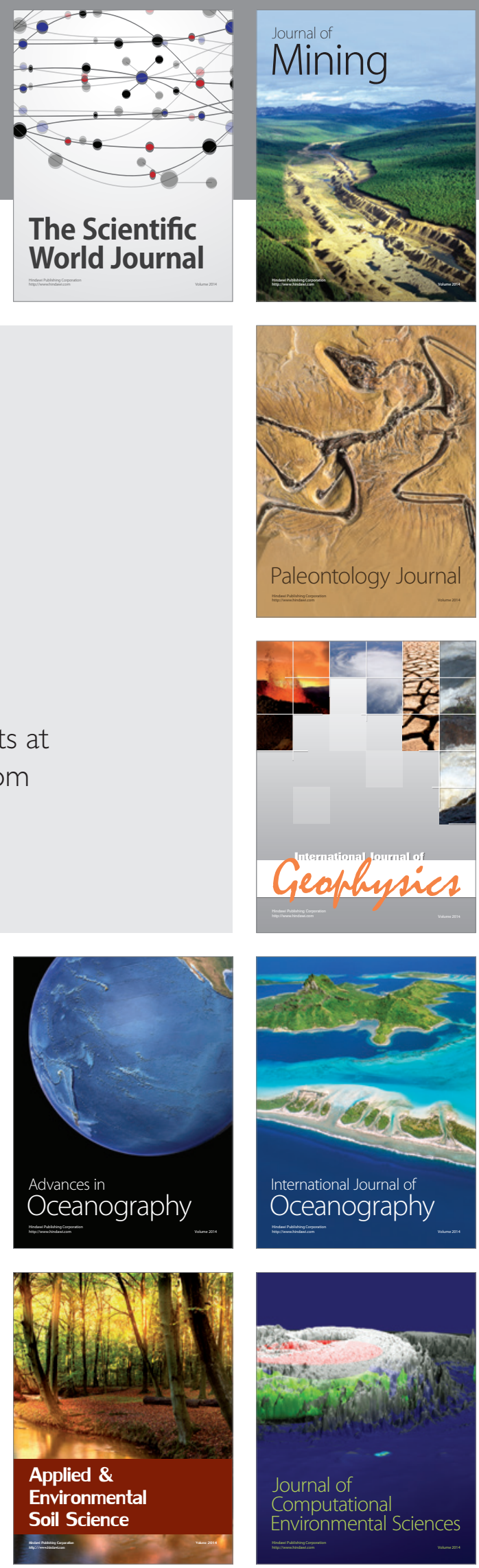